\title{
AS SOCIEDADES ANÔNIMAS DE CAPITAL AUTORIZADO E DE CAPITAL ABERTO.
}

PROF. RUBENS REQUIÃO

(Catedrático de Direito Comercial)

O estudo das sociedades anônimas, em nosso país, sofreu profundas modificações, em face de recente legislação. Convém, pois, reelaborar a classificação das sociedades anônimas, a partir da formação do capital social. É o que se pretende neste trabalho.

- Classificação atual das sociedades anônimas. As sociedades anônimas podem, quanto à forma de constituição de seu capital, adotar três modalidades: sociedade anônima de capital integralmente subscrito, que é a comum, de que trata a Lei n. ${ }^{\circ} 2.627$, de 1940; sociedade anônima de capital autorizado, criada pela Lei n. ${ }^{\circ} 4.728$, de 14 de julho de 1965; e as sociedades anônimas de capital aberto, disciplinadas pela Resolução n. ${ }^{\circ}$ 106, de janeiro de 1969, do Banco Central do Brasil.

A sociedade anônima de capital integralmente subscrito é a tradicionalmente existente em nosso Direito. Os fundadores incorporam a sociedade, determinando o valor do capital social, que deverá ser subscrito, sem o que ela não se forma. Qualquer aumento do capital deverá ser deliberado pela assembléia geral, importando conseqüentemente na reforma dos estatutos.

A sociedade de capital autorizado pode ser constituída com capital subscrito inferior ao consentido expressamente pelo estatuto social. Fixado o capital nominal, será êle realizado em parte, e a diretoria tem podêres para efetuar novas chamadas do capital dentro do limite da autorização, sem necessidade de permissão da assembléia geral e sem reforma dos estatutos.

E a sociedade de capital aberto é a que democratiza o seu capital, acolhendo um número mínimo de acionistas fixado pelo ConseIho Monetário Nacional, através de resoluções do Banco Central do Brasil. 
Tanto a sociedade de capital integralmente constituído como a de capital autorizado podem ser sociedades "fechadas" ou de "famí. lia", cujas ações na sua maioria pertencem a um grupo restrito de acionistas ou aos membros de uma só família, que mantém o contrôle da administração em suas mãos. Mas, como veremos, a sociedade de capital autorizado deve ser o primeiro passo para a abertura do capital social, pois a sociedade de capital aberto tem necessidade de aumentar o seu número de acionistas de dois em dois anos, como consta da Resolução n. ${ }^{\circ}$ 106. E para isso, não necessitará êsse tipo de sociedade anônima de alterar periòdicamente os seus estatutos.

Passaremos a estudar apenas as duas últimas modalidades de sociedades anônimas, pois o tipo tradicional e comum não oferece novidade.

1 Sociedade anônima de capital autorizado. Não há porque se confundir o conceito de sociedade anônima de capital aberto, com a de sociedade anônima de capital autorizado. São duas espécies bein distintas, que no entanto se podem fundir. A sociedade de capital aberto pode ser constituída também com o capital autorizado. Não há inconveniente na justaposição das duas modalidades de formação de capital numa só sociedade. A sociedade de capital aberto, tem o seu capital democratizado, isto é, diluído em maior quantidade de acionistas, de forma a se caracterizar pela participação popular no seu quadro de acionistas. A sociedade de capital autorizado, de que agora cuidaremos, é disciplinada pelo artigo 45 , da Lei $n .^{\circ} 4.728$, de 1965 , e se caracteriza por ser constituída com capital subscrito inferior ao autorizado pelos estatutos sociais. Não depende, ao contrário da sociedade de capital aberto, de autorização ou contrôle do Banco Central do Brasil para dessa maneira se organizar.

Para obviar o inconveniente de que cada aumento de capital seja precedido da autorização da assembléia de acionistas com a alteração dos estatutos, a Lei do Mercado de Capitais ( $n .^{\circ}$ 4.728), permitiu que, por antecipação, indique-se o capital final a ser realizado, cujos aumentos progressivos assim se consideram prèviamente autorizados. Mas a realização dêsse capital se faz paulatinamente, sem necessidade de outra formalidade que não a da deliberação da diretoria ou da assembléia geral.

A grande vantagem dêsse sistema de formação do capital social é permitir que a sociedade obtenha auto-financiamento de seu capital de giro, de conformidade com suas necessidades financeiras, com a venda de suas ações, sem maiores obstáculos ou formalismos. Para isso a lei dispõe que se pode dispensar o direito de preferência dos 
antigos acionistas, evitando-se a procrastinação dos trinta dias no mínimo que the são, nas sociedades anônimas comuns, marcados para o exercício dêsse direito; independe também das formalidades exigidas nas sociedades anônimas comuns para a subscrição de ações; a sociedade pode adquirir as suas próprias ações mediante a aplicação de lucros acumulados ou capital excedente, e sem redução do capital subscrito. A qualquer momento a diretoria pode emitir c colocar novas ações, sem quaisquer outras formalidades, a não ser a prévia audiência do Conselho Fiscal.

Após essa exposição teórica, vale exemplificar concretamente: suponhamos uma sociedade anônima com o capital autorizado de NCr\$100.000,00. Não é necessário, logo de comêço, a realização de tal volume de capital. Inicia-se, assim, a sociedade, por exemplo, com a chamada de $\mathrm{NCr} \$ 15.000,00,15 \%$ (quinze por cento) do capital que é o mínimo fixado pelo Banco Central para a integralização da subscrição das ações dessas sociedades. Posteriormente, conforme as necessidades sociais, a diretoria determina nova colocação de ações, em lotes da quantidade que desejar, e assim sucessivamente até atingir-se o capital autorizado sendo sempre no mínimo de $15 \%$ a integralização inicial. Mas, nesse caso, o capital autorizado pode ser aumentado, independentemente de subscrição de ações, ou com subscrição imediata, de apenas parte do acréscimo. Não é preciso, como se vê, que o aumento seja coberto pela subscrição dos acionistas, mas apenas fica previsto e autorizado, para futuras subscrições de ações.

O artigo 46, da Lei n. ${ }^{\circ} 4.728$, de 1965, determina que o estatuto dessas sociedades regulará obrigatòriamente: I - a emissão e colocação das ações com prévia aprovação da assembléia geral ou por deliberação da diretoria; II - as condições de subscrição e integralização a serem observadas pela assembléia geral ou pela diretoria, na emissão e colocação das ações de capital autorizado; III a emissão e colocação das ações com ou sem preferência para os acionistas da sociedade, e as condições do exercício do direito de preferência quando houver.

Devemos, ainda, considerar as seguintes regras: as ações não poderão ser ao portador, mas nominativas ou nominativas endossáveis; não se admite emissão de ações de gôzo ou fruição, ou de partes beneficiárias; a sociedade declarará em todos os seus papéis ou documentos a sua qualidade de sociedade anônima de capital autorizado, com o montante do seu capital subscrito e integralizado; importâncias correspondentes à subscrição das ações poderão ser recebidas pela sociedade, e independem de depósito bancário exigido 
pela lei; o capital em circulação da sociedade corresponde ao subscrito menos as ações adquiridas e em tesouraria, que não darão direito a voto, enquanto não forem novamente colocadas no mercado.

Comentamos que a sociedade de capital autorizado pode excluir o direito de preferência dos acionistas, na subscrição das novas ações emitidas. Mas êsse direito não poderá ser negado, nem pela assembléia geral nem pelos estatutos, quando forem emitidas por valor inferior ao de sua cotação em Bôlsa, se as ações da sociedade forem negociáveis nas Bôlsas de Valôres, ou por valor inferior ao do patrimônio líqüido, se as ações da sociedade não tiverem cotação nas Bôlsas de Valôres. Adiantamos aqui que sòmente as sociedades anônimas de capital aberto é que poderão ter suas ações cotadas na Bôlsa de Valôres, pois só elas são suscetíveis e obrigadas ao registro naquela instituição.

Por fim, a Lei criou as opções para a subscrição futura, de ações. Essa prática, segundo nos parece, era desconhecida entre nós, pois prevalecia o princípio legal da necessária preferência aos antigos acionistas. A opção de venda de ações futuras, a serem emitidas, é comum nos Estados Unidos, cujo mercado de capitais atinge a volume extraordinário. Essas opções para subscrição futura podem ser transferidas, constituindo um contingente ponderável de papéis para o mercado de capitais. Para tanto, todavia, é necessário que o estatuto ou a assembléia geral estabeleçam as condições da emissão e venda das opções para a subscrição futura de ações. Aliás, a sociedade de capital autorizado foi transposta para o nosso direito da experiência norte-americana, que deu um enorme estímulo às operações bolsistas, dinamizando ainda mais o seu poderoso mercado de capitais.

2 Sociedade de capital aberto. A fim de corrigir as distorções que o uso comercial havia acarretado ao sistema das sociedades anônimas, pondo-a a serviço de interêsses familiares ou de pequenos grupos fechados, o govêrno passou a estimular a abertura dessas sociedades ao investimento de novos acionistas. Esse processo que se denomina democratização do capital social, visa a permitir que a poupança particular participe do desenvolvimetno econômico, pela sua aplicação através de ações.

A primeira tentativa levada a efeito pelo Conselho Monetárı Nacional, consubstanciada nas Resoluções n. ${ }^{\circ}$ s 16 e 26, do Banco Central do Brasil, resultou em insucesso, face às bases irreais em que fôra lançada. A abertura de capital escudada sobretudo na negociabilidade das ações e no número elevado de acionistas não foi de molde a ensejar a proliferação de sociedades de capital aberto, pois, sem embargo dos incentivos fiscais estimulantes para difundir 
- sistema, apenas 265 sociedades anônimas participaram do movimento, democratizando seu capital.

Em virtude do insucesso da primeira tentativa, e em face das insistentes solicitações das classes empresariais, o govêrno foi levado a rever as antigas resoluções no sentido de adotar bases mais realistas e condizentes com a estrutura empresarial de nosso país. Daí a elaboração de novos critérios, consubstanciados na Resolução n. ${ }^{\circ} 106$.

Compreendendo e levando em consideração a diversificada estrutura econômica das empresas, decorrentes do grau de desenvolvimento das várias regiões econômicas e tendo em vista também a capacidade de poupança nos diferentes Estados e territórios, a Resolução n. ${ }^{\circ} 106$, tomando por base a sede das emprêsas, decidiu dividir o país em três grupos regionais.

1. Grupo - Acre, Alagoas, Amazonas, Ceará, Distrito Federal, Goiás, Maranhão, Mato Grosso, Pará, Paraíba, Piauí, Rio Grande do Norte, Sergipe e Territórios.

2. Grupo - Bahia, Espírito Santo, Minas Gerais, Paraná, Pernambuco, Rio de Janeiro, Rio Grande do Sul, e Santa Catarina.

3. ${ }^{\circ}$ Grupo - Guanabara e São Paulo.

Dividido o país territorialmente em três grupos ou regiões, a Resolução estabelece as bases quantitativas da democratização do capital, que diz respeito à faixa de $20 \%$ (vinte por cento) do total das ações ordinárias emitidas, não consideradas as em tesouraria (as não lançadas no mercado). Assim os vinte por cento das ações ordinárias devem ser distribuídos, tendo em vista o capital das sociedades e a localização de sua sede, segundo os seguintes critérios:

a) as sociedades que possuam capital subscrito de $\mathrm{NCr} \$$ 100.000,00 a NCr\$500.000,00;

1. Grupo: 100 acionistas, nenhum dêles com menos de 20 ações;

2. ${ }^{\circ}$ Grupo: 150 acionistas, nenhum dêles com menos de 35 ações;

3. ${ }^{\circ}$ Grupo: 250 acionistas, nenhum dêles com menos de 75 ações;

b) as sociedades que possuam capital de $\mathrm{NCr} \$ 500.001,00$ a $\mathrm{NCr} \$$ 1.000.000,00:

1. Grupo: 150 acionistas, nenhum dêles com menos de 30 ações; 
2. Grupo: 200 acionistas, nenhum dêles com menos de 60 ações;

3. ${ }^{\circ}$ Grupo: 350 acionistas, nenhum dêles com menos de 60 ações;

c) as sociedades que possuam capital igual ou superior a $\mathrm{NCr} \$$ 1.000.001,00:

1. Grupo: 200 acionistas, nenhum dêles com menos de 50 ações;

2. ${ }^{\circ}$ Grupo: 350 acionistas, nenhum dêles com menos de 75 ações;

3. ${ }^{\circ}$ Grupo: 500 acionistas, nenhum dêles com menos de 100 ações.

Para efeito da democratização do capital e na composição dos grupos de acionistas que deterão $20 \%$ do total de ações ordinárias, emitidas, observadas as limitaçães estabelecidas, a participação de cada acionista será considerada apenas até o montante máximo de $1 \%$ (um por cento) do total de ações ordinárias emitidas, mesmo que - acionista possua participação superior.

Temos, assim, os elementos necessários para a transformação da sociedade de "capital fechado" em sociedade anônima de "capital aberto". Tomemos, então uma sociedade anônima no Paraná, com o capital de $\mathrm{NCr} \$ 1.000 .000,00$. Para obter a emissão do certificado de sociedade anônima de capital aberto, necessita, portanto, de ter $20 \%$ de seu capital assim dividido (supondo-se que tenha apenas ações ordinárias ou comuns de $\mathrm{NCr} \$ 1,00$ cada uma):

a) de suas ações em número de um milhão, vinte por cento, ou sejam 200.000 ações, devem estar em mãos de 200 acionistas no mínimo;

b) como os acionistas subscrevem ações em diferentes quantidades, devido o seu poder aquisitivo, nenhum dos duzentos acionistas pode ter menos de 60 ações e não mais de 1.000 ações. Se ultrapassar êste número, para efeito do enquadramento da sociedade como de capital aberto, considera-se apenas o limite de 1.000 ações, isto é, 1\% do total das ações emitidas.

Observe-se que a lei estabelece os limites mínimos dentro dos quais se organiza a sociedade. Esse limite mínimo, em nosso exemplo, levaria a sociedade a ter duzentos acionistas, cada um com 1.000 ações, pois só assim conseguiria atingir a quota de $20 \%$ do capital subscrito democràticamente, ou sejam 20\%, ou 200.000 ações. Pros- 
seguindo-se no exemplo, se 190 acionistas subscrevem 1.000 ações, mas os restantes subscrevem 500 ações cada uma, a sociedade não atinge o grau de democratização necessário, pois então terá nos $20 \%$ do capital, 200 acionistas, os quais detêm apenas 195.000 ações. É preciso, portanto, que concorram mais 10 acionistas, cada um subscrevendo 500 ações. Atinge-se, no exemplo, o grau de democratização com a subscrição de $20 \%$ das ações, com 210 acionistas.

Pode ocorrer, segundo técnica do mercado de capitais, que as ações ordinárias sejam tomadas, em parte, por fundos de investimento. Prevendo essa possibilidade, a Resolução dispõe que para o efeito de cálculo de número de acionistas, as ações ordinárias de propriedade de fundos de investimento serão considerados como pertencentes a um número de acionistas proporcional ao número de participantes do fundo, na razão de 1 acionista para cada 500 partiticipantes do fundo, até o limite máximo de 25 acionistas por fundo, respeitado o número de ações exigido para cada acionista.

Se, por outro lado, as ações forem de valor nominal superior a NCr\$1,00, para o cálculo do número de ações exigido para cada acionista, serão consideradas como equivalentes a tantas ações quanto fôr o número que expresse em cruzeiros novos o valor nominal da ação.

A Resolução, com efeito, no item VII, diz que as ações de valor superior a NCr\$1,00, serão consideradas como equivalentes de tantas ações quanto fôr o número que expresse em cruzeiros novos - valor nominal. Assim, uma ação de $\mathrm{NCr} \$ 5,00$ será considerada como equivalente a 5 ações de $\mathrm{NCr} \$ 1,00$.

Mas é possível, naturalmente, fazer os cálculos, tendo em vista - valor da ação, como procedemos acima, podendo ser de $\mathrm{NCr} \$$ $5,00, \mathrm{NCr} \$ 10,00$ ou de qualquer outro valor, sem necessidade de efetuar o cálculo partindo da unidade monetária, ou seja de um cruzeiro nôvo (NCr\$ 1,00).

São essas as condições quantitativas para a obtenção de certificado de sociedade de capital aberto. Vejamos quais as condições qualitativas que se referem a tôdas as sociedades anônimas, com exclusão daquelas que estiverem impedidas por legislação especial.

a) manter suas ações registradas para negociação em uma oJ mais Bôlsas de Valôres do País. E sempre obrigatório o registro na Bôlsa sob cuja zona de ação se localiza a sede da emprêsa, sendo êste considerado como o primeiro registro. Nos subseqüentes registros, fixarão os Conselhos de 
Administração das demais Bôlsas desconto na contribuição periódica nunca inferior a $50 \%$ da mesma;

b) constar expressamente de seus estatutos sociais:

1 - plena conversibilidade entre as formas de ações ord:nárias existentes, quando houver mais de uma, a critério do acionista;

2 - desdobramento de títulos múltiplos, efetuado a preço não superior ao custo; e

3 - fixação do prazo máximo de 4 meses para o pagàmento de dividendos aprovados em Assembléia Geral e distribuição de ações provenientes de aumento de capital.

c) inexistência de qualquer espécie de restrição estatutária ou contratual que impeça ou dificulte a livre negociação de suas ações, a qualquer tempo.

Cumprindo essas condições a emprêsa está habilitada a requerer - certificado. Mas êsse certificado de sociedade de capital aberto, tenha-se em consideração, é válido apenas por dois anos. Cumpridos os dois anos no regime indicado, pode êle ser prorrogado por períodos sucessivos de dois anos se, ao término de cada período, a sociedade provar que atende às exigências de número mínimo de acionistas, detentores do mínimo indicado de ações, com acréscimo de $10 \%$ sôbre as condições exigidas para o período anterior, até que atinja $49 \%$ de seu capital em ações ordinárias.

Como se vê, a Resolução visa à democratização final de $49 \%$ do capital social representados por ações ordinárias. Essa meta de democratização, segundo nossos cálculos, progredindo 10\% por ano sôbre a percentagem de capital e número de acionistas, a cada período de dois anos, levará mais de vinte anos para ser alcançada. Daí porque, se impõe que a sociedade seja também de capital autorizado para permitir a emissão periódica de ações sem maiores formalismos. O pedido de renovação de certificado sòmente será aceito se der entrada no Banco Central do Brasil até 30 dias, no máximo, antes do término do prazo de validade do certificado em poder da interessada.

A Resolução n. 106 facilita às sociedades que pretendem pela primeira vez democratizar o capital social a realização dêsse desiderato. Para isso, ser-lhes-á fornecido certificado provisório, pelo prazo de um ano, a partir da emissão, desde que as ações sejam lançadas ao público, comprovando-se por contrato celebrado com instituição financeira autorizada a operar como colocadora de ações e títulos 
mobiliários (sociedades corretoras), contrato êsse visando a atingir, no período de validade do certificado emitido, as condições previstas para a obtenção do certificado definitivo.

Anualmente as sociedades de capital aberto são obrigadas, para a manutenção da validade de seu certificado, a remeter, na data correspondente ao certificado, ao Banco Central do Brasil, certidão das Bôlsas de Valôres onde estejam registradas, que contenha os seguintes dados:

a) capital social vigente

b) total das ações e debêntures emitidas, seu valor nominal e demais características;

c) cotações, mínima e máxima, no decorrer do período a que se referir;

d) se, no período da informação, a Bôlsa fêz ou recebeu reclamações sôbre a sociedade ou seus administradores;

e) valor patrimonial da ação.

Às Bôlsas de Valores devem ser encaminhadas tôdas as reclàmações formuladas por acionistas ou debenturistas sôbre sociedade nelas registradas ou seus administradores, as quais serão levadas pela mesma instituição ao Banco Central do Brasil, em expediente devidamente informado. A Bôlsa, portando, em face da reclamação ou denúncia, deverá, proceder a uma sindicância para averiguar a legitimidade da reclamação, a fim de informar eficientemente o Banco Central.

O Banco Central do Brasil ficou com a faculdade de exigir, além das demais prescrições legais e regulamentares, das sociedades consideradas de capital aberto, a fiel observância do registro perante êle efetuado, de várias informações ou documentos aludidos no artigo 20 , da Lei $4.728 / 65$, ou sejam:

a) natureza, detalhe e periodicidade da publicação de informações sôbre a situação econômica e financeira da pessoa jurídica, suas operações, administração e acionistas que controlam a maioria do seu capital votante;

b) organização do balanço e das demonstrações de resultado, padrões de organização contábil, relatórios e pareceres de auditores independentes registrados no Banco Central;

c) manutenção de mandatários para a prática dos atos relacionados ao registro de ações e obrigações nominativas, ou nominativas endossáveis.

Devem, também, essas sociedades de capital aberto atentar para 
a fiel observância das seguintes obrigações definidas no art. 34 da Lei do Mercado de Capitais:

- As sociedades por ações deverão completar, dentro de quinze dias do pedido do acionista ou interessado, os atos de registro, averbação, conversão ou transferência de ações.

- Se o estatuto social admite mais de uma forma de ação não poderá limitar a conversibilidade de uma forma em outra, ressalvada a cobrança do custo de substituição dos certificados.

- As sociedades, cujas ações sejam admitidas à cotação das Bôlsas de Valores, deverão colocar à disposição dos acionistas, no prazo máximo de 60 dias a contar do arquivamento da ata da Assembléia Geral, as ações correspondentes ao aumento de capital mediante incorporação de reservas, correção monetária ou subscrição integral.

- As sociedades por ações são obrigadas a comunicar, às Bôlsas nas quais os seus títulos são negociados, a suspensão transitória de transferência de ações no livro competente, com 15 dias de antecedência, aceitando o registro das transferências que lhes forem apresentadas com data anterior.

- É facultado às sociedades por ações o direito de suspender os serviços de conversão, transferência e desdobramento de ações, para atender a determinações de assembléia, não podendo fazê-lo, porém, por mais de 90 dias intercalados durante o ano, nem por mais de 15 dias consecutivos.

Com base nas informações recebidas, seja da sociedade ou de terceiro através da Bôlsa, poderá o Banco Central do Brasil verificar e declarar a perda da qualidade de sociedade de capital aberto ou a mudança de classificação do respectivo certificado, comunicando o fato à interessada, às Bolsas e ao Departamento do Impôsto de Renda. Explica-se a comunicação ao Impôsto de Renda, pois, perdida a qualidade de sociedade de capital aberto, decaem esta e seus acionistas dos favores dos estímulos fiscais à democratização do capital.

- Estímulos fiscais à abertura do capital. É tal o interêsse do govêrno de que as emprêsas democratizem seu capital, abrindo-o à participação da poupança popular, propiciando dessa forma melhor distribuição da riqueza, que oferece estímulos tributários para a consecução dessa política. 
Os estímulos e benefícios são os seguintes:

a) As sociedades de capital aberto não estão atingidas pela tributação com o impôsto de renda sôbre a distribuição de lucros, hoje de $5 \%$, devido além do impôsto de $30 \%$, sôbre os lucros apurados (tributados).

b) $O$ montante dos dividendos até o limite de $6 \%$ sôbre o capital distribuido aos acionistas, é dedutível como despesa operacional da pessoa jurídica.

c) A tributação dos dividendos de ação ao portador em que não forem identificados os títulos, bem como de ações nominativas, poderá ser feita exclusivamente na fonte à base de 15\%, sem necessidade de o beneficiário submeter o rendimento a tributação na declaração da pessoa física, sòmente incluindo o acréscimo patrimonial na declaração de bens. 